\title{
Determining the Minimal Important Difference for the Wound-QoL Questionnaire
}

\author{
Janine Topp' \\ Christine Blome' \\ Matthias Augustin' \\ Nicole Mohr (D) \\ Eike Sebastian Debus ${ }^{2}$ \\ Holger Diener ${ }^{2}$ \\ Rachel Sommer' \\ 'Institute for Health Services Research in \\ Dermatology and Nursing (IVDP), \\ German Center for Health Services \\ Research in Dermatology (CVderm), \\ University Medical Center Hamburg- \\ Eppendorf (UKE), Hamburg, Germany; \\ ${ }^{2}$ Department of Vascular Medicine, \\ University Medical Center Hamburg- \\ Eppendorf (UKE), Hamburg, Germany
}

Correspondence: Rachel Sommer Institute for Health Services Research in Dermatology and Nursing (IVDP), German Center for Health Services Research in Dermatology (CVderm), University Medical Center HamburgEppendorf (UKE), Hamburg, Germany Tel +49 (0) 40741024724 Fax +49 (0) 40741040160

Email r.sommer@uke.de
Background: The questionnaire for the quality of life with chronic wounds (Wound-QoL) is a valid and reliable instrument to determine the disease-specific health-related QoL of patients with chronic wounds. For the interpretation of HRQoL scores, it is additionally important to know which differences in scores are considered meaningful. The minimal important difference (MID) is defined as a change in HRQoL that a patient would consider meaningful, such that the patient would judge a treatment to be beneficial and worthy of repeating.

Objective: To interpret changes in the Wound-QoL scores and draw conclusions regarding the relevance of detected changes; the purpose of this study was to estimate the MID of the Wound-QoL global score and its subscales for patients with chronic wounds.

Patients and Methods: Patients completed the Wound-QoL before and four to six weeks after treatment and additionally gave a global rating of wound status change after treatment. The global rating of change served as an anchor question. MIDs were calculated based on an anchor-based and a distribution-based method.

Results: In total, 227 patients participated in the study. The mean age of the study population was $66.9( \pm 12.7)$ median was 69.5 , and $51.5 \%$ of the patients were female. MIDs for the Wound-QoL global score ranged from 0.47 to 0.52 , proposing an overall estimation of 0.50 .

Conclusion: The results can be used to measure and interpret changes in wound-specific QoL over time.

Keywords: MID, minimal important difference, health-related quality of life, chronic wounds

\section{Introduction}

Chronic wounds can cause pain, reduce mobility and lead to social isolation and further impairments in everyday life. Accordingly, the health-related quality of life (HRQoL) of patients with chronic wounds is substantially impaired. ${ }^{1-3}$ Chronic wounds commonly persist for several months or years and treatment is very complex and time consuming. In many cases, quality care, including identification of the wound cause, is lacking. Improving patients' HRQoL and decreasing the burden of disease are important goals in the long-lasting process of wound treatment. ${ }^{4} \mathrm{HRQoL}$ is thus also an essential outcome for evaluating treatment success in patients with chronic wounds. Numerous generic and disease-specific measurement instruments have been developed in the past decades. In order for these instruments to be used in clinical practice or clinical trials, they should fulfil defined psychometric requirements, such as reliability and validity. ${ }^{5}$ For the interpretation of HRQoL scores, it is additionally important to know which differences in scores are considered meaningful. The minimal important 
difference (MID) is defined as a change in HRQoL considered as meaningful, in order to judge a treatment to be beneficial and worthy of repeating. ${ }^{6}$

A frequently used instrument to assess HRQoL in patients with chronic wounds is the Wound-QoL questionnaire. It was developed based on three wound-specific HRQoL instruments, aiming to condense the list of items to include the most necessary items and harmonise the response format. ${ }^{8}$ The final psychometrically validated version of the Wound-QoL questionnaire contains 17 items and allows for conclusions to be made regarding the overall wound-specific HRQoL as well as its individual domains. It has been proven to be a wellunderstandable, valid and highly reliable questionnaire that is suitable for use in clinical trials as well as clinical practice. ${ }^{9-11}$ The Wound-QoL showed good internal consistency, with high Cronbach's alpha for all the subscales and in the global scale $(>0.8)$. Convergent validity was satisfactory as indicated by correlations with the generic HRQoL as measured by the EQ-5D (range $=0.5-0.7$ ) and another measure of wound-specific HRQoL, the FLQA-wk global score $(r>0.8) .{ }^{9}$ Test-retest reliability ranged from $\mathrm{r}=0.79$ for the subscale "psyche" to 0.86 in the total score. ${ }^{10}$ The Wound-QoL has been translated into many languages and is therefore used internationally. ${ }^{12,13}$ Until now, the absence of a MID has led to limitations in the interpretation of changes in Wound-QoL scores and made drawing conclusions regarding the relevance of detected changes difficult.

The MID can be determined based on different methods, which can be assigned to two categories: distribution-based and anchor-based methods. ${ }^{14,15}$ Distribution-based methods use indicators of the statistical distribution (eg, effect size, standard deviation) to determine what constitutes a minimally relevant change. Referring to this, empirical evidence suggests that half a standard deviation (SD) approximates the MID for several patient-reported outcomes. ${ }^{16}$ In contrast, anchor-based methods make use of external anchors: patient- or clinician-reported global ratings of overall change in health or disease severity are used to assign patients into different groups reflecting no change, slight positive or negative change and large positive or negative change. These global ratings of change are then compared to the change in the HRQoL score over time. ${ }^{17,18}$

MID estimates for patient-reported outcomes are much needed to determine the clinical importance of a given change regarding a particular measurement instrument. According to the U.S. Food and Drug Administration
(FDA), MID estimates are an essential component of comprehensive assessments of clinical utility. ${ }^{19}$ Thus, the aim of this study was to determine MIDs for the Wound-QoL global score and its subscales using a distribution-based and an anchor-based method. Such MIDs will particularly facilitate use of the Wound-QoL in aggregate analyses, such as in clinical research and quality assurance.

\section{Patients and Methods}

To determine MIDs of the Wound-QoL in patients with chronic wounds, data from a previously conducted longitudinal validation study were used. ${ }^{9}$ Patients were recruited from two specialised wound centres and four community practices from March 2014 to March 2016. Patients were eligible to participate in the study if they were at least 18 years of age, had a chronic wound by definition and had no lack of mental, physical, or linguistic ability to take part in a questionnaire study. Detailed information on the study can be found elsewhere. ${ }^{9}$

For the MID subanalysis, we analysed the HRQoL of patients with chronic wounds at baseline (t1) and four to six weeks later $(\mathrm{t} 2)$. In the meantime, patients received wound-specific treatment in accordance with the respective wound etiology and status. To assess HRQoL, the Wound-QoL questionnaire written in German was used. The validated instrument consists of 17 items that can be assigned to three subscales: body, psychological wellbeing and everyday life (Figure 1).

A global score quantifying overall HRQoL can be determined. The total score for each subscale and the global score each range from 0 (= no impairment) to 4 (= maximum impairment).

As an anchor, we used a patient-reported global rating of change regarding the overall wound status. At $\mathrm{t} 2$, patients were asked to describe their wound status compared to before treatment, ie, at baseline. The status was rated on a 5-point Likert scale ranging from 1 (= much better) to 5 (= much worse).

We calculated the Wound-QoL global and subscale scores for each patient and time point and determined individual changes in the Wound-QoL score over time ( $\mathrm{t} 2-\mathrm{t} 1)$. Half a SD of the Wound-QoL global score and subscale scores at $\mathrm{t} 1$ was used to represent the distribution-based MID. The approach to determine SD-based important difference values in this patient sample is backed by the fact that the distribution of Wound-QoL total values at baseline is in line with other study data from real-world populations. For this, a sufficient degree of representation of typical wounds 


\section{Wound-QoL questionnaire on quality of life with chronic wounds}

With the following questions, we aim to find out how your chronic wound(s) affect(s) your quality of life.

Please tick one box per line!

In the last seven days ...

\begin{tabular}{|c|c|c|c|c|c|c|}
\hline 1 & ...my wound hurt & $\mathrm{O}$ & $\mathrm{O}$ & $\mathrm{O}$ & $\mathrm{O}$ & $\mathrm{O}$ \\
\hline 2 & ...my wound had a bad smell & $\mathrm{O}$ & $\mathrm{O}$ & $\mathrm{O}$ & $\mathrm{O}$ & $\mathrm{O}$ \\
\hline 3 & ...there was a disturbing discharge from the wound & $\mathrm{O}$ & $\mathrm{O}$ & $\mathrm{O}$ & $\mathrm{O}$ & $\mathrm{O}$ \\
\hline 4 & ...the wound has affected my sleep & $\mathrm{O}$ & $\mathrm{O}$ & $\mathrm{O}$ & $\mathrm{O}$ & $\mathrm{O}$ \\
\hline 5 & ...the treatment of the wound has been a burden to me & $\mathrm{O}$ & $\mathrm{O}$ & $\mathrm{O}$ & $\mathrm{O}$ & $\mathrm{O}$ \\
\hline 6 & ...the wound has made me unhappy & $\mathrm{O}$ & $\mathrm{O}$ & $\mathrm{O}$ & $\mathrm{O}$ & $\mathrm{O}$ \\
\hline 7 & $\begin{array}{l}\text {...I have felt frustrated because the wound is taking so long to } \\
\text { heal }\end{array}$ & $\mathrm{O}$ & $\mathrm{O}$ & $\mathrm{O}$ & $\mathrm{O}$ & $\mathrm{O}$ \\
\hline 8 & ...I have worried about my wound & $\mathrm{O}$ & $\mathrm{O}$ & $\mathrm{O}$ & $\mathrm{O}$ & 0 \\
\hline 9 & $\begin{array}{l}\text {...I have been afraid of the wound getting worse or of new } \\
\text { wounds appearing }\end{array}$ & $\mathrm{O}$ & $\mathrm{O}$ & $\mathrm{O}$ & $\mathrm{O}$ & $\mathrm{O}$ \\
\hline 10 & ...I have been afraid of knocking the wound & $\mathrm{O}$ & $\mathrm{O}$ & $\mathrm{O}$ & $\mathrm{O}$ & $\mathrm{O}$ \\
\hline 11 & ...I have had trouble moving about because of the wound & $\mathrm{O}$ & $\mathrm{O}$ & $\mathrm{O}$ & $\mathrm{O}$ & $\mathrm{O}$ \\
\hline 12 & ...climbing stairs has been difficult because of the wound & $\mathrm{O}$ & $\mathrm{O}$ & $\mathrm{O}$ & $\mathrm{O}$ & $\mathrm{O}$ \\
\hline 13 & $\begin{array}{l}\text {...I have had trouble with day-to-day activities because of the } \\
\text { wound }\end{array}$ & $\mathrm{O}$ & $\mathrm{O}$ & $\mathrm{O}$ & $\mathrm{O}$ & $\mathrm{O}$ \\
\hline 14 & ...the wound has limited my leisure activities & $\mathrm{O}$ & $\mathrm{O}$ & $\mathrm{O}$ & $\mathrm{O}$ & $\mathrm{O}$ \\
\hline 15 & ...the wound has forced me to limit my activities with others & $\mathrm{O}$ & $\mathrm{O}$ & $\mathrm{O}$ & $\mathrm{O}$ & $\mathrm{O}$ \\
\hline 16 & $\begin{array}{l}\text {...I have felt dependent on help from others because of the } \\
\text { wound }\end{array}$ & $\mathrm{O}$ & $\mathrm{O}$ & $\mathrm{O}$ & $\mathrm{O}$ & $\mathrm{O}$ \\
\hline 17 & ...the wound has been a financial burden to me & $\mathrm{O}$ & $\mathrm{O}$ & $\mathrm{O}$ & $\mathrm{O}$ & $\mathrm{O}$ \\
\hline
\end{tabular}

Figure I Wound-QoL questionnaire.

can be assumed. Moreover, the kind and proportion of different wound types largely is in line with claims data from Germany on large cohorts of routine patients. ${ }^{20}$

For determination of the anchor-based MID, we focused on two groups: patients reporting positive change and patients reporting negative change regarding their wound status according to the anchor question. The respective mean change in the Wound-QoL for the group of patients reporting positive change corresponded to the anchor-based MID for improvement and the mean change in the Wound-QoL for the group of patients reporting negative change corresponded to the MID for deterioration. Patients who did not answer the Wound-QoL questionnaire at both time points or the anchor question at $\mathrm{t} 2$ were excluded from the analysis.

Analyses were performed using SPSS Statistics for Microsoft Windows, Version 22.0 (IBM Corporation, Armonk, NY).

\section{Results}

In total, 227 patients participated in the study. Mean age was $66.9( \pm 12.7)$, ranging from 18 to 95 years with a median of 69.5 years and $51.5 \%$ of the patients were 
female (Table 1). The sample included patients with different wound etiologies: leg ulcers $(n=123)$, diabetic or ischemic foot ulcers $(n=12)$, pressure ulcers $(n=6)$ and other wounds $(n=68)$. The mean duration of wound persistence among all patients was 25.9 months $( \pm 66.1$ ), ranging from 0.4 to 804 months. Of 227 patients at baseline (t1), 209 completed the follow-up survey (t2). Participants were excluded from the analysis if the questionnaire was not completed, the anchor question was not answered or the Wound-QoL contained more than four missing items such that, according to the user's manual, no global score could be calculated.

The mean Wound-QoL global score significantly decreased $(\mathrm{t} 1: 1.89 \pm 0.95, \mathrm{t} 2: 1.50 \pm 0.91, \mathrm{p}<0.001)$, ie, HRQoL improved over time. The greatest improvement was observed for the subscale psychological well-being $(\mathrm{t} 1: 2.34 \pm 1.11, \mathrm{t} 2: 1.83 \pm 1.04, \mathrm{p}<0.001)$. Improvement regarding the subscale body (t1: $1.54 \pm$ 0.95 , t2: $1.17 \pm 0.90, \mathrm{p}<0.001)$ was similar to the improvement the subscale everyday life $(\mathrm{t} 1: 1.89 \pm 1.2$, t2: $1.58 \pm 1.23, \mathrm{p}<0.001$ ) (Table 1) Histograms of the Wound-QoL scores differences $\mathrm{t} 2-\mathrm{t} 1$ are presented in the Supplement.

Overall, improvement in the wound status could also be observed with regard to the anchor question: 114 patients reported a better or much better wound status after compared to treatment, 13 reported worse or much worse wound status and 67 patients perceived no change. The correlation between the perceived change in wound status (anchor question) and the change in the Wound-QoL global score from $\mathrm{t} 1$ to $\mathrm{t} 2$ was positive $(\mathrm{r}=0.45, \mathrm{p}<0.001)$.

The distribution-based MID estimate was \pm 0.47 for the global score. For the subscales, MID estimates ranged from \pm 0.47 for the subscale body to \pm 0.62 for the subscale everyday life (Table 2).

The anchor-based MID estimates for the Wound-QoL global score were -0.52 for patients reporting positive change (ie, improvement) and 0.47 for patients reporting negative change (ie, decline) in HRQoL. Contrary to the distribution-based MIDs for the subscales of the WoundQoL questionnaire, the threshold for meaningful positive change was lowest for the subscale everyday life $(-0.41)$ and highest for the subscale psychological well-being $(-0.63)$. The subsample for the determination of MID estimates for a decline in HRQoL considering the global score as well as the subscales was small $(n=10)$. Table 3 provides a summary of the MID estimates for improvement and deterioration separately.

\section{Discussion}

This study aimed to establish MIDs for the Wound-QoL and thus facilitate an understanding of what change in HRQoL is meaningful. Two statistical methods using patient-reported HRQoL score were applied: a distribution-based method and an anchor-based method. According to the distribution-based method, a change in the Wound-QoL global score (range: 04) of 0.47 can be considered meaningful. The anchor-based method confirmed an MID of 0.47 for deterioration and determined an MID of -0.52 for improvement in HRQoL. The MID estimates for the subscales of the Wound-QoL questionnaire were, for the most part, slightly higher than those for the global score. Furthermore, differences between the anchor-based and distribution-based methods were more pronounced. Due to the small subsample reporting a worsening of the wound status, the anchor-based CID estimates for deterioration in HRQoL for the global score as well as the subscales must be interpreted with caution. However, the anchor-based MID for deterioration, at least for the global score, was similar to the estimate for improvement and similar to the distribution-based MID. This indicates that the determined estimate reflects a meaningful negative change for patients with chronic wounds.

Identifying similar MID estimates while using different methods strengthens our findings considering the MID for the Wound-QoL global score. However, the strengths and limitations of both methods need to be considered. ${ }^{21}$ A limitation of the distribution-based method is that it does not refer to information of clinical relevance provided by the patients themselves, ${ }^{18,22}$ although research suggests that patients' capacity to discriminate between HRQoL states corresponds well to approximately half an SD. ${ }^{16}$ In contrast, anchor-based methods do include the patients' valuation and thus allow for direct MID estimates. Asking patients to state their perceived global change in their health state, as done in this study, is a wellestablished way of including the patients' perspective in determining the threshold for minimal but meaningful change. ${ }^{6,23,24}$ However, the two methods used are of statistical nature, although using patient-reported information. Changes in HRQoL may be statistically significant based on a mathematical basis but may be of little or no importance to patients. ${ }^{7}$ In studies based on large sample sizes, it is likely that small effects become statistically significant, while patients would not consider the change to be meaningful or the treatment to be worthy of repeating. In further research, additional evidence for adequate 
Table I Demographic and Clinical Characteristics of the Study Participants

\begin{tabular}{|c|c|c|}
\hline \multicolumn{3}{|l|}{ Demographic characteristics } \\
\hline \multicolumn{3}{|l|}{ Gender (n, \%) } \\
\hline Female & 110 & 48.5 \\
\hline Male & 117 & 51.5 \\
\hline Age in years $(n$, mean $\pm S D$, $)$ & 227 & $66.9 \pm 12.7$ \\
\hline Min,max; median & & $18-96 ; 69.5$ \\
\hline Skewness (SE); kurtosis (SE) & & $-0.8(0.2) ; 0.9(0.3)$ \\
\hline Duration of wound persistence (months) & 221 & $25.9 \pm 66.1$ \\
\hline Min,max; median & & $0.4-804 ; 12$ \\
\hline Skewness (SE); kurtosis (SE) & & $8.5(0.2) ; 91.2(0.3)$ \\
\hline \multicolumn{3}{|l|}{ Clinical characteristics } \\
\hline \multicolumn{3}{|l|}{ Wound etiology (n, \%)* } \\
\hline Leg ulcers & 123 & 54.2 \\
\hline Diabetic or ischemic foot ulcers & 12 & 5.3 \\
\hline Pressure ulcers & 6 & 2.6 \\
\hline Other (arterial, surgical, traumatic, burns) & 68 & 30.0 \\
\hline Wound-QoL at $\mathrm{tl} \mathrm{I}^{* *}(\mathrm{n}$, mean $\pm \mathrm{SD})$ & 221 & $1.9 \pm 0.9$ \\
\hline Min, max; median & & $0-4 ; 1.8$ \\
\hline Skewness (SE); kurtosis (SE) & & $0.0(0.2) ;-0.98(0.3)$ \\
\hline Reliability (n, Cronbach's alpha) & 203 & 0.928 \\
\hline Subscale body ( $n$, mean \pm SD) & 221 & $1.5 \pm 1.1$ \\
\hline Min, max; median & & $0-4 ; 1.4$ \\
\hline Skewness (SE); kurtosis (SE) & & $0.4(0.2) ;-0.6(0.3) 0.754$ \\
\hline Reliability (Cronbach's alpha) & 215 & $2.3 \pm 1.1$ \\
\hline Subscale psychological well-being $(n$, mean $\pm S D)$ & 223 & $0-4 ; 2.4$ \\
\hline Min, max; median & & $-0.3(0.2) ;-0.9(0.3)$ \\
\hline Skewness (SE); kurtosis (SE) & & 0.861 \\
\hline Reliability (Cronbach's alpha) & 218 & $1.9 \pm 1.2$ \\
\hline Subscale everyday life $(n$, mean $\pm S D)$ & 220 & $0-4 ; 1.8$ \\
\hline Min, max; median & & $(0.1)(0.2) ;-1.2(0.3)$ \\
\hline Skewness (SE); kurtosis (SE) & & 0.929 \\
\hline Reliability (Cronbach's alpha) & 211 & \\
\hline Wound-QoL at t2*** $(n$, mean $\pm S D)$ & 207 & $1.5 \pm 0.9$ \\
\hline Min, max; median & & $0-4 ; 1.4$ \\
\hline Skewness (SE); kurtosis (SE) & & $0.4(0.2) ;-0.3(0.3)$ \\
\hline Reliability (n, Cronbach's alpha) & 184 & 0.937 \\
\hline Subscale body $(n$, mean $\pm S D)$ & 207 & $1.2 \pm 0.9$ \\
\hline Min, max; median & & $0-4 ; 1.0$ \\
\hline Skewness (SE); kurtosis (SE) & & $0.9(0.2) ; 0.4(0.3)$ \\
\hline Reliability (Cronbach's alpha) & 202 & 0.814 \\
\hline Subscale psychological well-being $(n$, mean $\pm S D)$ & 207 & $1.8 \pm 1.0$ \\
\hline Min, max; median & & $0-4 ; 1.8$ \\
\hline Skewness (SE); kurtosis (SE) & & $0.2(0.2) ;-0.8(0.3)$ \\
\hline Reliability (Cronbach's alpha) & 199 & 0.842 \\
\hline Subscale everyday life $(n$, mean $\pm S D)$ & 206 & $1.6 \pm 1.2$ \\
\hline Min, max; median & & $0-4 ; 1.4$ \\
\hline Skewness (SE); kurtosis (SE) & & $0.4(0.2) ;-0.9(0.3)$ \\
\hline Reliability (Cronbach's alpha) & 196 & 0.932 \\
\hline
\end{tabular}

Notes: *Missing data; **At baseline; ***4 to 6 weeks after baseline.

Abbreviations: $\mathrm{n}$, number of participants; SD, standard deviation; SE, standard error. 
Table 2 Distribution-Based MID Estimates for the Global Score and the Subscales

\begin{tabular}{|c|c|c|}
\hline & $\mathbf{n}$ & $\begin{array}{l}\text { MID at tI* } \\
\text { SD }=0.5(95 \% \mathrm{Cl})\end{array}$ \\
\hline Wound-QoL global score & 221 & $0.47(0.87 ; 1.20)$ \\
\hline Subscale body & 221 & $0.47(0.87 ; 1.01)$ \\
\hline Subscale psychological well-being & 223 & $0.56(1.03 ; 1.18)$ \\
\hline Subscale everyday life & 220 & $0.62(1.15 ; 1.30)$ \\
\hline
\end{tabular}

Note: *At baseline.

Abbreviations: MID, minimal important difference, $n$, number of participants; SD, standard deviation; $\mathrm{Cl}$, confidence interval.

Table 3 Anchor-Based MID Estimates for the Global Score and the Subscales

\begin{tabular}{|c|c|c|c|c|}
\hline & \multicolumn{2}{|c|}{$\begin{array}{l}\text { Subgroup of } \\
\text { Patients } \\
\text { Reporting } \\
\text { Positive } \\
\text { Change } \\
\text { (Wound } \\
\text { Improvement) }\end{array}$} & \multicolumn{2}{|c|}{$\begin{array}{l}\text { Subgroup } \\
\text { of Patients } \\
\text { Reporting } \\
\text { Negative } \\
\text { Change }\end{array}$} \\
\hline & $\mathbf{n}$ & MID* & $\mathbf{n}$ & MID \\
\hline Wound-QoL global score & 89 & -0.52 & 10 & 0.47 \\
\hline Subscale body & 89 & -0.57 & 9 & 0.42 \\
\hline $\begin{array}{l}\text { Subscale psychological well- } \\
\text { being }\end{array}$ & 90 & -0.63 & 10 & 0.44 \\
\hline Subscale everyday life & 89 & -0.41 & 10 & 0.58 \\
\hline
\end{tabular}

Note: *Negative values of MID represent a clinical improvement.

Abbreviations: MID, minimal important difference; $n$, number of participants.

MIDs could be collected by asking patients to evaluate hypothetical scenarios about change in HRQoL as measured with the Wound-QoL. ${ }^{25-27}$ Such approach would increase the fact that these differences are important to patients rather than merely statistically relevant. In addition, the change ratings may be susceptible to recall bias, as they require a comparison of a health state in the past with the current health state. ${ }^{15,18}$ To balance the inherent limitations of any anchor question, it is recommended to determine MIDs based on multiple independent anchors, including the patient's and clinician's perspective. ${ }^{18}$ Accordingly, MIDs identified in the present study, which were based on a single anchor question and a distributionbased approach only, should be confirmed in future studies using different clinician- and patient-reported anchors.

Moreover, future studies should consider the anchor question to be sensitive enough to detect small but meaningful change. In the present study, the global rating of change was assessed on a 5-point Likert scale, ranging from a much worse to a much better health state. In contrast to a more differentiated and thus more sensitive anchor question, such as the 15-point scoring system of the Global Rating of Change Score, ${ }^{6,25}$ a 5-point Likert scale may be limited in differentiating between patients perceiving slight changes and patients perceiving greater changes. This differentiation is particularly important when determining minimal but meaningful changes in patients' HRQoL and may have caused a marginal overestimation of the MID. In addition, future studies should determine potential differences in MIDs between subgroups, eg, by wound etiology, which was not possible in the current study due to the small sample size in the respective subgroups.

The Wound-QoL is a valid and reliable instrument that is used to determine the disease-specific HRQoL of patients with chronic wounds. It has been applied in clinical trials, economic evaluations and clinical practice. ${ }^{11,28-30}$ This first attempt to determine MID estimates for the Wound-QoL questionnaire and its subscales offers guidance on how to interpret changes in HRQoL. Summarising the determined MID estimates of the global score by taking the mean of all estimates calculated in this study and tending toward a slightly more conservative approach, we propose a change of 0.50 for the Wound-QoL questionnaire as an appropriate MID for patients with chronic wounds. Due to greater discrepancies in MID estimates observed for the three subscales of the Wound-QoL questionnaire, a general recommendation for subscales is not made. As all items of the Wound-QoL questionnaire are rated on the same 5-point Likert scale, an average change of 0.5 units per item, ie a one-unit change in every second item, would result in a meaningful change from the patient's perspective. This threshold will support the evaluation of treatment benefits in clinical trials.

\section{Conclusion}

In summary, a change of 0.50 in the Wound-QoL questionnaire is recommended as an appropriate MID for patients with chronic wounds. When using the Wound-QoL in daily practice, such an MID may also be a useful indicator of relevant treatment success. However, in clinical practice, use of the MID and thresholds for the global score is not as instructive as use of the conclusions from single items. For this, a further approach toward more value-based clinical decisions would be the structured inclusion of single items 
that indicate specific therapeutic measures. Such an attempt was started recently with the introduction of the Wound-Act, a tool translating burden identified by single items into treatment goals. ${ }^{11}$ Both methodologies should be tested for clinical feasibility in future studies.

\section{Acknowledgments}

The authors thank the Scientific Communication Team of the IVDP, in particular Sara Tiedemann and Mario Gehoff, for copy editing. This was an unfunded study.

\section{Disclosure}

Dr Holger Diener reports personal fees from URGO GMBH, LAMED, Smith \& Nephew, and KCI, outside the submitted work. The authors report no other conflicts of interest in this work.

\section{References}

1. Herber OR, Schnepp W, Rieger MA. A systematic review on the impact of leg ulceration on patients' quality of life. Health Qual Life Outcomes. 2007;5:1-12. doi:10.1186/1477-7525-5-44

2. Augustin M, Herberger K, Rustenbach SJ, Schäfer I, Zschocke I, Blome C. Quality of life evaluation in wounds: validation of the Freiburg Life Quality Assessment-wound module, a disease-specific instrument. Int Wound J. 2010;7:493-501. doi:10.1111/j.1742481X.2010.00732.x

3. Herberger K, Rustenbach SJ, Haartje O, et al. Quality of life and satisfaction of patients with leg ulcers - results of a community-based study. VASA. 2011;40:131-138. doi:10.1024/0301-1526/a000083

4. Augustin M, Mayer A, Goepel LM, Baade K, Heyer K, Herberger K. Cumulative Life Course Impairment (CLCI): a new concept to characterize persistent patient burden in chronic wounds. Wound Med 2013;1:2-6. doi:10.1016/j.wndm.2013.06.001

5. Augustin M, Langenbruch AK, Herberger K, Baade K, Goepel L, Blome C. Quality of life measurement in chronic wounds and inflammatory skin diseases: definitions, standards and instruments. Wound Med. 2014;5:29-38. doi:10.1016/j.wndm.2014.04.008

6. Jaeschke R, Singer J, Guyatt GH. Measurement of health status. Ascertaining the minimal clinically important difference. Control Clin Trials. 1989;10:407-415. doi:10.1016/0197-2456(89)90005-6

7. Hays RD, Woolley JM. The concept of clinically meaningful difference in health-related quality-of-life research. How meaningful is it? Pharmacoeconomics. 2000;18:419-423. doi:10.2165/00019053200018050-00001

8. Blome C, Baade K, Debus ES, Price P, Augustin M. The "WoundQoL": a short questionnaire measuring quality of life in patients with chronic wounds based on three established disease-specific instruments. Wound Repair Regen. 2014;22:504-514. doi:10.1111/ wrr. 12193

9. Augustin M, Conde Montero E, Zander N, et al. Validity and feasibility of the Wound-QoL questionnaire on health-related quality of life in chronic wounds. Wound Repair Regen. 2017;25:852-857. doi:10.1111/wrr.12583

10. Sommer R, Augustin M, Hampel-Kalthoff C, Blome C. The Wound-QoL questionnaire on quality of life in chronic wounds is highly reliable. Wound Repair Regen. 2017;25:730-732. doi:10.1111/ wrr. 12578
11. Augustin M, Baade K, Herberger K, et al. Use of the WoundQoL instrument in routine practice: feasibility, validity and testing of an implementation tool. Wound Med. 2014;4:4-8. doi:10.1016/j. wndm.2014.04.001

12. Fagerdahl AM, Bergstrom G. Translation and validation of a wound-specific, quality-of-life instrument (the Wound-QoL) in a Swedish population. Ostomy Wound Manage. 2018;64:40-46. doi:10.25270/owm.2018.5.4046

13. Gamus A, Kaufman H, Keren E, Brandin G, Peles D, Chodick G. Validation of "Wound QoL" Hebrew version disease-specific questionnaire for patients with lower extremity ulcerations. Int Wound J. 2018;15:600-604. doi:10.1111/iwj.12903

14. Jayadevappa R, Cook R, Chhatre S. Minimal important difference to infer changes in health-related quality of life-a systematic review. J Clin Epidemiol. 2017;89:188-198. doi:10.1016/j. jclinepi.2017.06.009

15. McGlothlin AE, Lewis RJ. Minimal clinically important difference: defining what really matters to patients. JAMA. 2014;312:1342-1343. doi:10.1001/jama.2014.13128

16. Norman GR, Sloan JA, Wyrwich KW. Interpretation of changes in health-related quality of life: the remarkable universality of half a standard deviation. Med Care. 2003;41:582-592. doi:10.1097/01. MLR.0000062554.74615.4C

17. Swartz RJ, Schwartz C, Basch E, et al. The king's foot of patientreported outcomes: current practices and new developments for the measurement of change. Qual Life Res. 2011;20:1159-1167. doi:10.1007/s11136-011-9863-1

18. Revicki D, Hays RD, Cella D, Sloan J. Recommended methods for determining responsiveness and minimally important differences for patient-reported outcomes. J Clin Epidemiol. 2008;61:102-109. doi:10.1016/j.jclinepi.2007.03.012

19. U.S. Department of Health and Human Services, Food and Drug Administration. Guidance for industry: patient-reported outcome measures: use in medical product development to support labeling claims. 2009.

20. Heyer K, Herberger K, Protz K, Glaeske G, Augustin M. Epidemiology of chronic wounds in Germany: analysis of statutory health insurance data. Wound Repair Regen. 2016;24(2):434-442. doi:10.1111/wrr.12387

21. King MT. A point of minimal important difference (MID): a critique of terminology and methods. Expert Rev Pharmacoecon Outcomes Res. 2011;11:171-184. doi:10.1586/erp.11.9

22. Engel L, Beaton DE, Touma Z. Minimal clinically important difference: a review of outcome measure score interpretation. Rheum Dis Clin North Am. 2018;44:177-188. doi:10.1016/j.rdc.2018.01.011

23. Basra MKA, Salek MS, Camilleri L, Sturkey R, Finlay AY. Determining the minimal clinically important difference and responsiveness of the Dermatology Life Quality Index (DLQI): further data. Dermatology. 2015;230:27-33. doi:10.1159/000365390

24. Alma HJ, de Jong C, Jelusic D, et al. Assessing health status over time: impact of recall period and anchor question on the minimal clinically important difference of copd health status tools. Health Qual Life Outcomes. 2018;16:130. doi:10.1186/s12955-018-0950-7

25. Staunton H, Willgoss T, Nelsen L, et al. An overview of using qualitative techniques to explore and define estimates of clinically important change on clinical outcome assessments. J Patient Rep Outcomes. 2019;3(16). doi:10.1186/s41687-019-0100-y

26. Hagg O, Fritzell P, Oden A, Nordwall A. Simplifying outcome measurement: evaluation of instruments for measuring outcome after fusion surgery for chronic low back pain. Spine. 2002;27:1213-1222. doi:10.1097/00007632-200206010-00014

27. Thissen D, Liu Y, Magnus B, et al. Estimating minimally important difference (MID) in PROMIS pediatric measures using the scale-judgment method. Qual Life Res. 2016;25:13-23. doi:10.1007/ s11136-015-1058-8 
28. Sommer R, Hampel-Kalthoff C, Kalthoff B, et al. Differences between patient- and proxy-reported HRQoL using the Wound-QoL. Wound Repair Regen. 2018;26:293-296. doi:10.1111/ wrr. 12662

29. Agbi KE, Carvalho M, Phan H, Tuma C. Case report: diabetic foot ulcer infection treated with topical compounded medications. Int J Pharm Compd. 2017;21:22-27.
30. Gutknecht M, Walzer S, Heyer K, et al. Costs of compression therapy in venous leg ulcers in Germany and modelling of the economic effects of regional disparities in health care. Value Health. 2015;18: A372. doi:10.1016/j.jval.2015.09.758

\section{Publish your work in this journal}

Patient Preference and Adherence is an international, peer-reviewed, open access journal that focusing on the growing importance of patient preference and adherence throughout the therapeutic continuum. Patient satisfaction, acceptability, quality of life, compliance, persistence and their role in developing new therapeutic modalities and compounds to optimize clinical outcomes for existing disease states are major areas of interest for the journal. This journal has been accepted for indexing on PubMed Central. The manuscript management system is completely online and includes a very quick and fair peer-review system, which is all easy to use. Visit http:// www.dovepress.com/testimonials.php to read real quotes from published authors. 